\title{
Trends and Fluctuations in Monetary Growth
}

Question - Is a 6 percent rate of growth in the money stock stimulative?

Reply - Not enough information has been supplied to answer with an unqualified yes or no. The information necessary for judging the aggregative effects of a certain growth rate in the money supply is outlined below. The main points are as follows: sustained trends in monetary growth tend to be associated with trends in the rate of inflation; substantial deviations of monetary growth from its trend tend to be reflected in fluctuations of production and employment.

\section{Essential Information}

Duration - An essential piece of information necessary to determine the effect of a certain growth rate of money is the time span over which this growth rate has been experienced, that is, the duration of the given growth rate. Monetary analysts generally agree that the growth rate of money for a single month, or even one quarter, does not accurately indicate the degree of monetary stimulus on aggregate economic activity. However, once a certain growth rate has been sustained for at least two consecutive quarters, many analysts consider this observation to be useful informa* tion for drawing general implications for the course of economic activity in subsequent quarters.

For example, from June to July 1972 the narrowly defined money stock rose at a 15 percent compounded annual rate. Based on that observation alone, not enough information is available to form an assessment about whether that given growth rate is stimulative or restrictive.

When this observation is taken in combination with the additional knowledge that the growth rate of the money stock for the 12 months ending July 1972 was 5.3 percent, one can make a conditional statement: if the jump in July was a temporary occurrence, a longerterm trend, such as the 5.3 percent growth, is a more reliable indicator of monetary tightness or ease. If on the other hand, the 15 percent growth rate were to be sustained for several months, it would represent a significant deviation from the prior trend and therefore would have an impact on future economic activity. Even though the magnitude and the time pattern of the impact are not known with certainty, the direction of influence can be ascertained reliably,

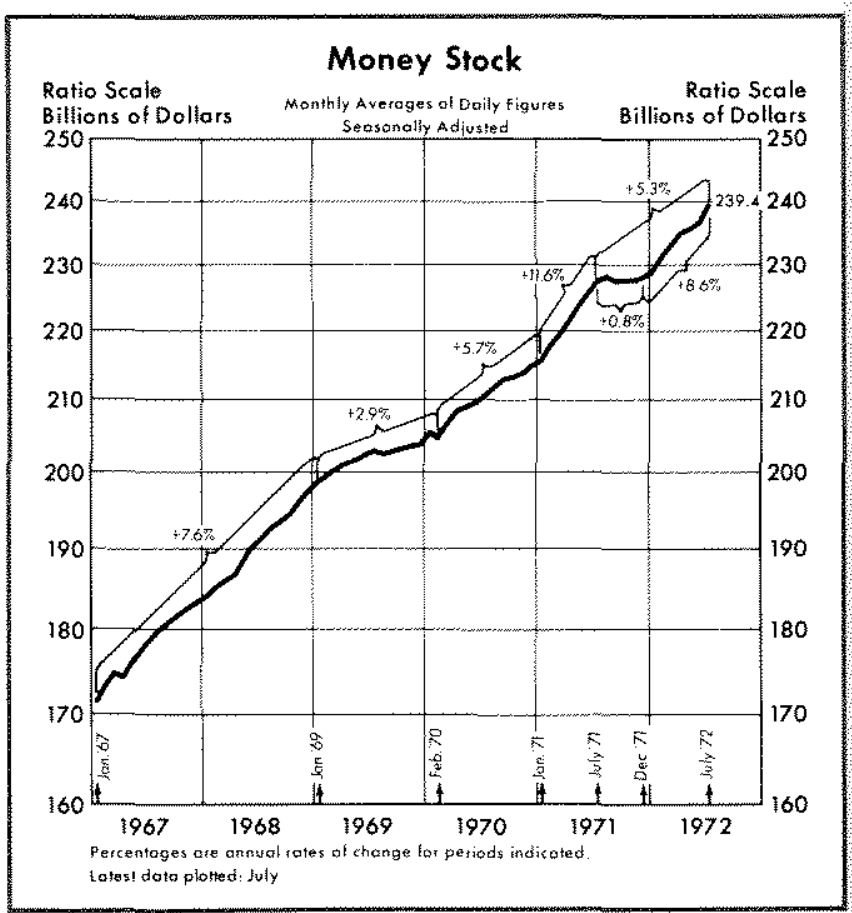

Initial conditions - Another piece of information that is required to make a statement about the degree and probable consequences of monetary tightness or ease is the nature of conditions which prevail at the time of the change in the growth rate. These initial conditions encompass the state of economic activity as a result of previous monetary actions as well as other factors. In other words, the analyst must answer the question - what is the prevailing stage in the process of adjustment of prices, output, and employment to all previous monetary injections or withdrawals and to all other factors which influence aggregate economic activity? The prevailing economic conditions may be such that the influence of a given growth rate of money at that point may be swamped, for a period of time, by the force of previous actions.

The answer to a question regarding the stimulus or restraint implied by a change in the growth rate of the money stock involves a separation of the influence of changes in the money stock on the various aggregate measures of the state of the economy. For instance, it is quite possible for a certain growth rate of money, such as 6 percent per year, to be consistent in the short run with rising prices and declining output and employment. 


\section{Fluctuations in Money Growth- The Short-Run Impact}

For illustration of these points relating to the effects of achieving a given rate of monetary growth, assume that the 6 percent growth rate of money marks a slowing from a prevailing higher trend rate. Historical evidence suggests that for several quarters following the initial slowing of money, the rate of growth of real production would tend to slow from what it had been and the rate of unemployment would rise. At the same time, however, the rate of price increase would tend to reflect for some time the prior rate of money growth.

Past experience regarding the relation between accelerations and decelerations in monetary growth on the one hand, and fluctuations in both the level of unemployment and the rate of real product growth on the other, is illustrated in the chart entitled "Fluctuations of Money Stock and Economic Activity," p. 8 of this article. The top line in the chart shows the percentage change of money stock in each quarter compared to the corresponding quarter a year earlier for the period 1952 through mid-1972. The second line from the top shows the corresponding percentage changes in real product growth, and the third lineoutput per person-provides an altemative measure of real aggregate production. The lower line is the measured rate of unemployment. The vertical shaded areas indicate periods of recession as determined by the National Bureau of Economic Research. ${ }^{x}$

The patterns in these series show that in most cases the peaks in the rates of growth of real output coincided with, or followed only one or two quarters after, the peaks in the rate of growth of the money supply. There were no instances when the growth of output continued to rise throughout an interval in which the rate of monetary growth contracted. Furthermore, there were no instances in which an accelerating growth in money was not accompanied or followed by a rising rate of production.

The analyst will not find on this chart, nor should he seek, a consistent lead or lag between monetary growth and real economic growth. The effect on output of accelerations and decelerations of money can vary from time to time, depending on the stage of adjustment of the economy to previous monetary shocks. Initial conditions may change and thereby infuence the timing of the observed response of output changes to monetary actions. Despite the shortcomings of the

1The first quarter of 1967, the so-called "mint-recession," is also shaded, even though it was not declared an "official" recession. chart as a tool for analysis, it serves as a useful device for illustrating relationships which are consistent with those derived in more detailed studies.

\section{Trends in Money Growth - The Long-Pun Impact}

The historical relationships between trends in money growth and trends in inflation are illustrated in the chart entitled "Monetary Growth and Prices," p. 9. As is always the case, but is also always worth reemphasizing, an observed relationship does not necessarily imply causality. However, both the U.S. and foreign experience ${ }^{2}$ are consistent with the proposition that in the long run the trend rate of growth of the money supply is the dominant determinant of the trend rate of growth of prices. ${ }^{3}$

The U.S. experience in the past twenty years consists of at least three periods marked by sustained increases in the trend rates of growth of the money stock. The behavior of prices has followed, with a lag of two or more years, a very similar pattern. The chart shows the most recent trend growth of money to have begun at the end of 1966 and continued through the second quarter of 1972 . This choice of beginning and ending points shows an average annual rate of growth in money of 6 percent in the past five and one-half years. However, it should be remembered that, as with the other basic trend periods indicated on the chart, this period is characterized by several shorter periods of deviations from the underlying trend shown, some of much slower growth in money, and some of much more rapid growth.

By reference to the accompanying table, one can observe the quarter-by-quarter pattern of monetary growth during the period by looking at the diagonal of this "rate-of-change triangle". Also, alternative breaking points within the past five and one-half

2See the accompanying article entitled "Production, Prices, and Money in Four Industrial Countries," this issue of the Review, pp. 11-15. Also see Michele Fratianni, "The Italian Case," and Manfred Neumann, "The German Case," in Karl Brunner et al., "The Monetary Fiscal Approach to Inflation: A Multi-Country Study" (paper presented at the Conference on Secular Inftation, National Bureau of Economic Research, November 5-6, 1971).

"See Leonall C. Andersen and Denis S. Karnosky, "The Appropriate Time Frame for Controlling Monetary Aggregates: the St. Louis Evidence" (paper presented at the Federal Reserve Bank of Boston Conference on "Controlling Monetary Aggregate II: The Implementation," Melvin Village, New Hampshire, September 8, 1972); Milton Friedman, The Optimum Quantity of Money and Other Essays (Chicago: Aldine Publishing Company, 1969); Irving Fisher, The Putchasing Poteer of Money (New York: Augustus M. Kelley, 1963); and Knut Wicksell, Interest and Prices (New York: Augustus M. Kelley, 1962). 


\section{Fluctuations of Money Stock and Economic Activity}
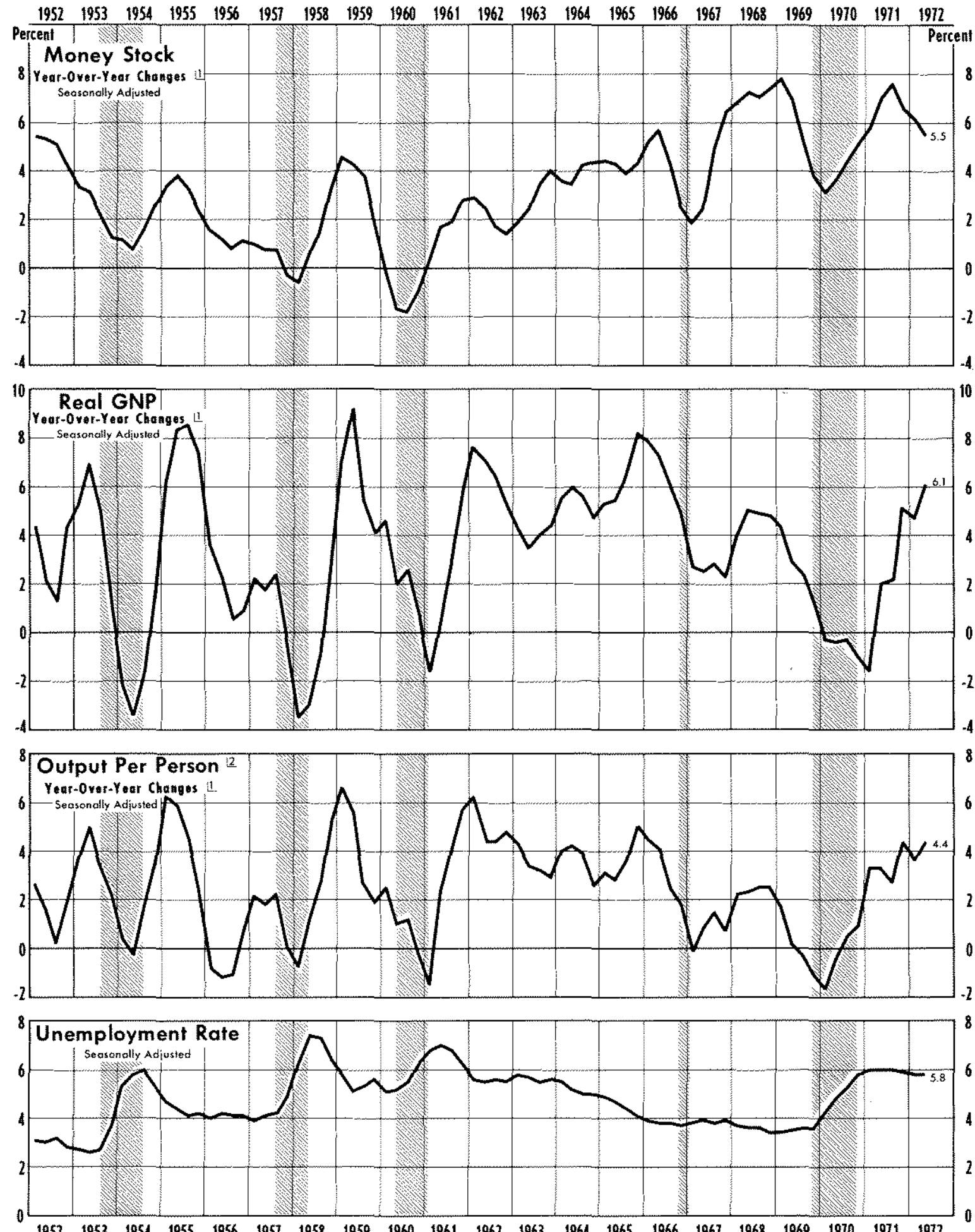

$\begin{array}{lllllllllllllllllllll}1952 & 1953 & 1954 & 1955 & 1956 & 1957 & 1958 & 1959 & 1960 & 1961 & 1962 & 1963 & 1964 & 1965 & 1966 & 1967 & 1968 & 1969 & 1970 & 1971 & 1972\end{array}$ The shaded areas shown in 1953-54, 1957.58, 1960-61. and 196970 represent periods of business recessions as defined by the Nationol Bureau of Economic Research. The shaded

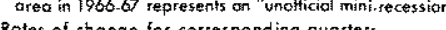

II Fotal private economyi tolal oulpul divided by the number of persons employed

latest data plotfed: 2nd quarter 


\section{Monetary Growth and Prices}

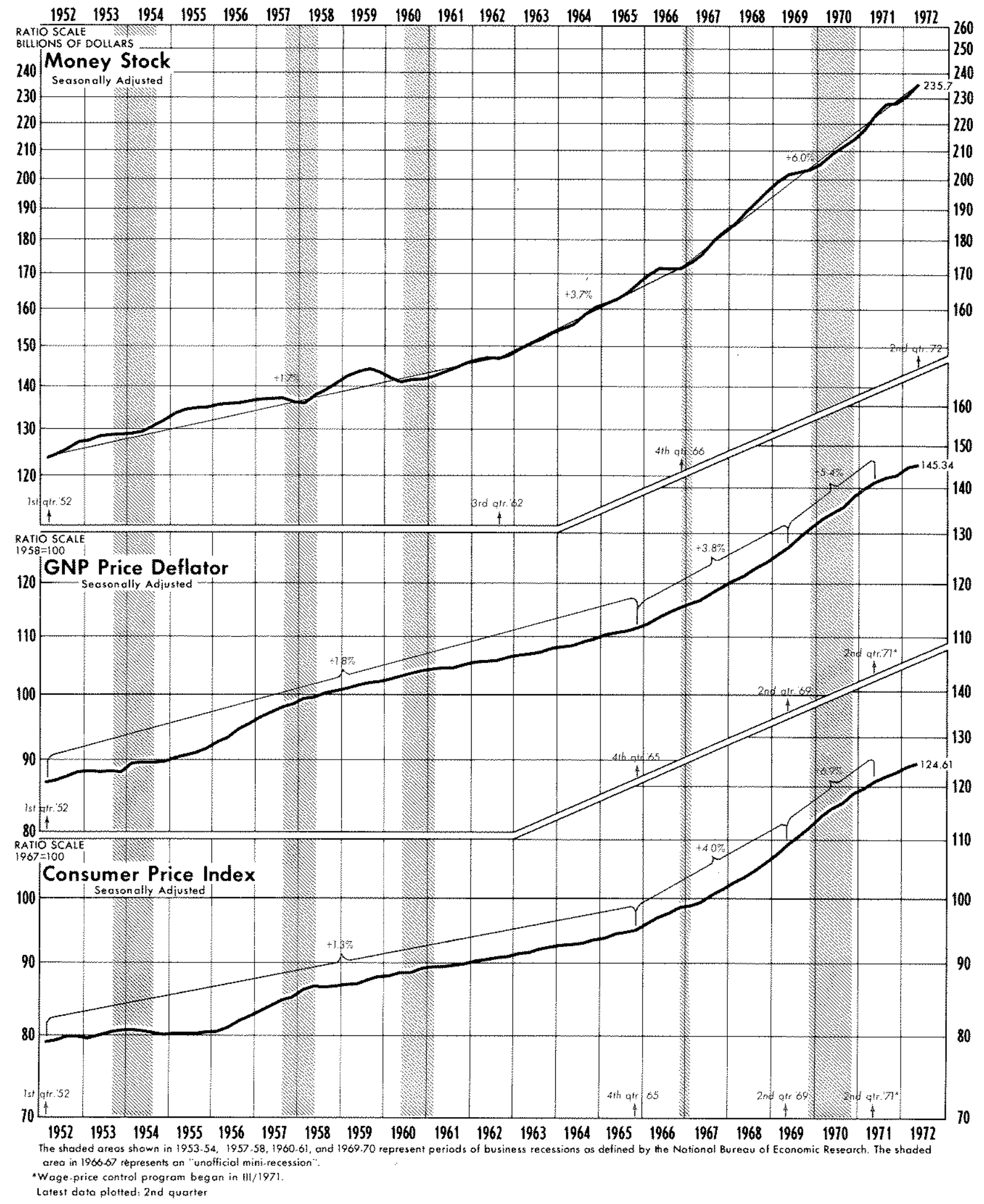




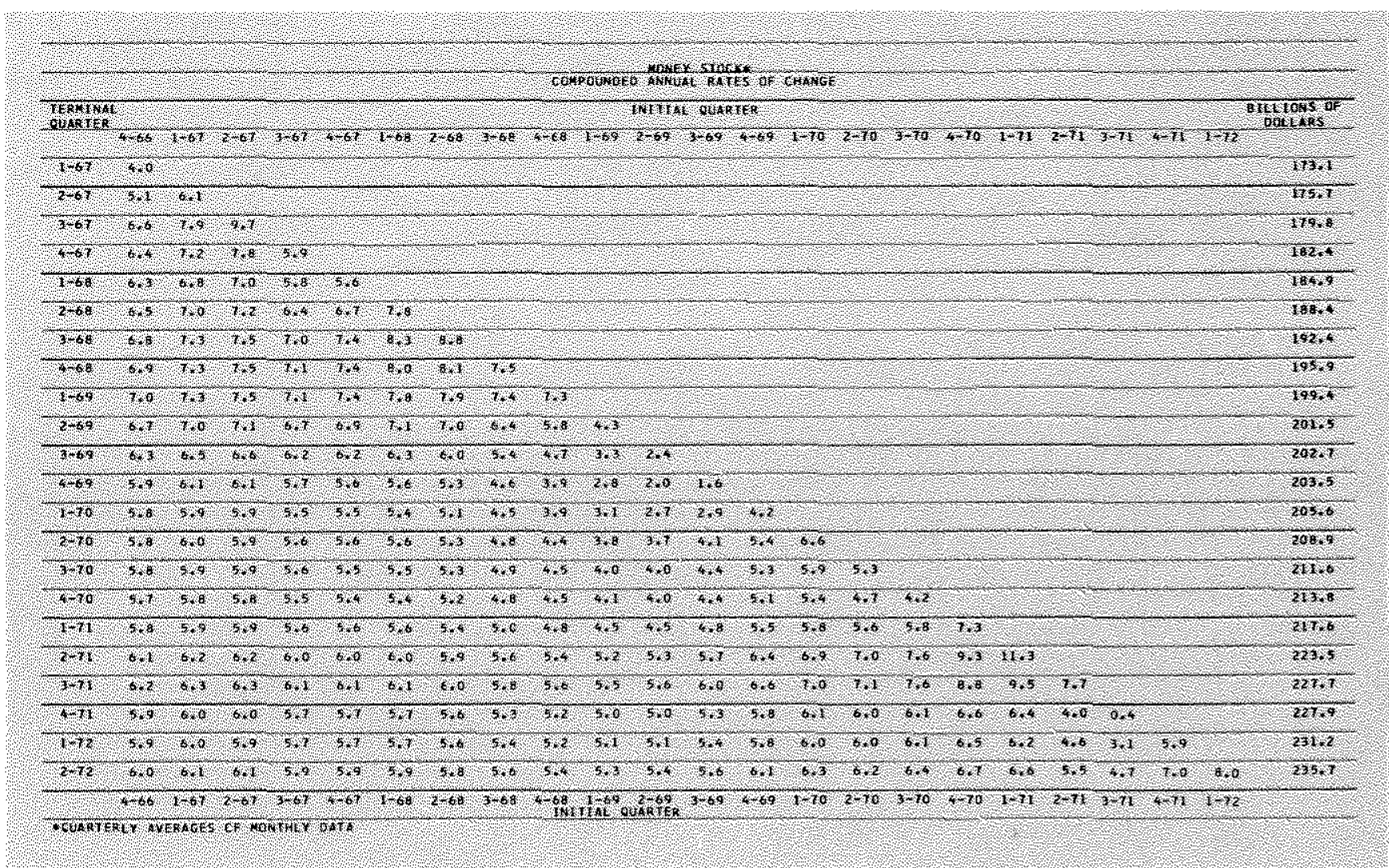

year period may be selected. For example, the growth of money from IV $/ 1966$ to IV $/ 1970$ was at a 5.7 percent rate, and from IV/1970 to II/1972 the growth of money was at a 6.7 percent rate.

While analysts may disagree as to the choice of the exact periods, the charts clearly show an increase in the trend rate of growth of the money stock over the past five to seven years. Previous experience suggests that this tendency will eventually be reflected in an upward trend in prices.

\section{Conclusion}

An answer to the original question of whether a certain growth rate of the money stock is stimulative is not possible without answering further questions. First, is that growth rate temporary or sustained? Second, what are the initial conditions? An increase in the rate of growth has little stimulative effect on total spending, prices, or output unless it is sustained for at least two quarters. If the new growth rate of money is sustamed, the short-run effect on total spending, prices, and output depends on the initial conditions.

Given that a particular growth in money is sustained, past experience suggests the following. First, there will likely be a stimulative effect on total spend- ing if the sustained money growth rate is more rapid than the previous trend growth rate of money and is greater than the normal variation about that trend. Second, the observed short-run effect on prices and real output growth is strongly influenced by prevailing economic conditions, that is, the current level of capacity utilization, price anticipations, the level of employment, and other factors. If there is "slack" in the economy and price anticipations are low, as in the early 1960s, increases in total spending induced by monetary actions will be reflected primarily in a step-up in real output growth in the short run. If employment, capacity utilization, and price anticipations are high, as in the late 1960s, total spending increases will be manifested less in output growth and more in price increases.

In general, the short-run response of real output growth to changes in the rate of growth of the money stock tends to be greater than the response of prices. However, a change in the trend rate of growth of money will eventually produce a corresponding change in the rate of increase in the price level. According to this analysis, reducing the rate of increase of prices from the rate fostered by an accelerated growth of money for an extended period subsequently could involve substantial costs in terms of reduced real output growth. 